\title{
CIRRHOTIC PATIENTS WITH ACUTE KIDNEY INJURY (AKI) HAVE HIGHER MORTALITY AFTER ABDOMINAL HERNIA SURGERY
}

\author{
PACIENTES CIRRÓTICOS COM LESÃO RENAL AGUDA TEM MAIOR MORTALIDADE APÓS \\ CIRURGIA DE HÉRNIA ABDOMINAL
}

\author{
Liliana DUCATTI ${ }^{1 \oplus}$, Luciana B. P. HADDAD ${ }^{1 \oplus}{ }^{\circ}$, Alberto MEYER $^{1 \oplus}{ }^{1}$, Lucas S. NACIF ${ }^{1 \oplus}$, Rubens M. ARANTES ${ }^{1 \oplus}$, \\ Rodrigo B. MARTINO ${ }^{1 \oplus}$, Vinicius ROCHA-SANTOS ${ }^{1 \oplus}$, Daniel R. WAISBERG ${ }^{1 \oplus}$, Rafael S. PINHEIRO ${ }^{1 \odot}$, \\ Luiz A.C. D’ALBUQUERQUE ${ }^{1 \oplus}$, Wellington ANDRAUS ${ }^{1 \oplus}$
}

\begin{abstract}
BACKGROUND: The incidence of abdominal hernia in cirrhotic patients is as higher as $20 \%$; in cases of major ascites the incidence may increase up to $40 \%$. One of the main and most serious complications in cirrhotic postoperative period (PO) is acute kidney injury (AKI). AIM: To analyze the renal function of cirrhotic patients undergoing to hernia surgery and evaluate the factors related to AKI. METHODS: Follow-up of 174 cirrhotic patients who underwent hernia surgery. Laboratory tests including the renal function were collected in the PO.AKI was defined based on the consensus of the ascite's club. They were divided into two groups: with (AKI PO) and without AKI. RESULTS: All 174 patients were enrolled and AKI occurred in 58 (34.9\%). In the AKI PO group, 74.1\% had emergency surgery, whereas in the group without AKI PO it was only $34.6 \%$.In the group with AKI PO, 90.4\% presented complications, whereas in the group without AKI PO they occurred only in $29.9 \%$. Variables age, baseline MELD, baseline creatinine, creatinine in immediate postoperative (POI), AKI and the presence of ascites were statistically significant for survival. CONCLUSIONS: There is association between AKI PO and emergency surgery and, also, between AKI PO and complications after surgery. The factors related to higher occurrence were initial MELD, basal $\mathrm{Cr}, \mathrm{Cr}$ POI. The patients with postoperative AKI had a higher rate of complications and higher mortality.

HEADINGS - Liver cirrhosis. Herniorrhaphy. Hernia. Acute kidney injury. Ascites.
\end{abstract}

RESUMO - RACIONAL: A incidência de hérnia abdominal em pacientes cirróticos é elevada, em torno de $20 \%$. Em casos de ascite volumosa, a incidência atinge valores até $40 \%$. Uma das principais e mais graves complicações no pós-operatório de correção de hérnias de pacientes cirróticos é a insuficiência renal aguda (IRA).Objetivo: Analisar a função renal de pacientes cirróticos submetidos a herniorrafias, comparando aqueles que apresentavam IRA pós-operatório com os demais, para determinar os fatores relacionados à sua ocorrência. MÉTODO: Seguimento de pacientes cirróticos submetidos à cirurgia de hérnia entre 2001 e 2014 no Serviço de Transplante de Fígado. Foram coletados exames laboratoriais para avaliar a função renal no pós-operatório rotineiramente. A IRA foi definida com base no consenso do clube da ascite em 2015. RESULTADOS: Dos 174 pacientes incluídos, ocorreu IRA em 58 pacientes (34,9\%). Houve diferença entre grupos para as seguintes variáveis: MELD inicial, creatinina basal e creatinina, o grupo com IRA apresentou medias superiores ao grupo que não apresentou IRA. No grupo IRA PO, 74,1\% das cirurgias, foram realizadas em caráter de emergência, enquanto que no grupo sem IRA no pós-operatório, 34,6\%. No grupo IRA 90,4\% dos indivíduos apresentaram complicações no pós-operatório, enquanto no grupo sem IRA $29,9 \%$. As variáveis idade, MELD inicial, creatinina basal e creatinina no pós-operatório inicial foram estatisticamente significantes na análise de sobrevida. CONCLUSÕES: Existe uma associação entre IRA pós-operatória e cirurgia de emergência e IRA pós-operatóri e complicações pós-operatórias. Os fatores relacionados à maior ocorrência de IRA em pacientes cirróticos submetidos à cirurgia de hérnia são o MELD inicial, creatinina basal, creatinina pós-operatória inicial. O preparo de pacientes cirróticos com hérnia abdominal antes de procedimentos cirúrgicos deve ocorrer sistematicamente, pois apresentam alta incidência de IRA pós-operatória.

DESCRITORES: Cirrose hepática. Herniorrafia. Hérnia. Injuria renal aguda. Ascite.

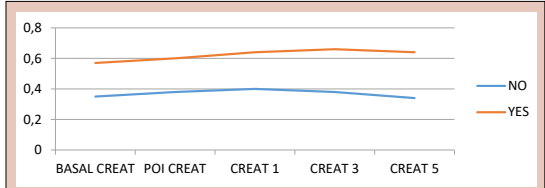

CREAT $=$ creatinine; $\mathrm{POI}=$ immediate postoperative; Anova for non-parametric repeated measures; red line patients with $\mathrm{AKI}$; black line without AKI

Figure 1 - Postoperative creatinine in cirrhotic patients who underwent herniorraphies: $A$ ) red line with $\mathrm{AKI} ; \mathrm{B})$ blue line without AKI

\section{Central message}

There is association between acute kidney injury in the postoperative period and emergency surgery and between it and complications after surgery, they had a higher rate of complications and higher mortality.

\section{Perspective}

To be able to identify the risk factors for AKI development in cirrhotic patients undergoing surgical procedures, in order to prevent this event, thus reducing complications in these patients
Fundings: None

Conflict of interest: None

Received: 23/04/2021

Accepted: 30/09/202 
INTRODUCTION

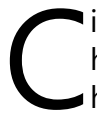
irrhosis represents a late stage of progressive hepatic fibrosis characterized by distortion of the hepatic structure and the formation of regenerative nodules. It's physiopathology involves progressive hepatic lesions resulting in portal hypertension and decompensation, including ascites, spontaneous bacterial peritonitis, hepatic encephalopathy, variceal bleeding, hepatorenal syndrome ${ }^{12}$, hepatocellular carcinoma ${ }^{17}$ and colon dysfunction ${ }^{6}$. It is the $8^{\text {th }}$ most common cause of mortality in the United States and $13^{\text {th }}$ worldwide, with $45.6 \%$ increase in mortality. It is generally considered irreversible in its more advanced stages, for which the only definitive treatment is liver transplantation?.

One of the principal and most serious complications of cirrhosis is acute kidney injury (AKI) ${ }^{11}$. Its appearance at any phase of cirrhosis is associated with greater morbimortality. Often, its progression leads the patient to renal replacement therapy (dialysis), either temporarily or permanently. In the long term, kidney transplantation may be necessary ${ }^{13}$. Almost $20 \%$ of patients with cirrhosis will develop AKI over the course of hospitalization, with mortality rates as high as $50-90 \%(3)$. Over $60 \%$ of all cases of $A K I$ in patients with cirrhosis are attributable to pre-renal factors, such as hypovolemia, hypoperfusion, massive renal vasoconstriction by systemic arterial and splanchnic vasodilation ${ }^{5}$.

Many recent studies have assessed the incidence of AKI, its evolution and treatment in patients with cirrhosis ${ }^{19}$. There is a lack, however, in the literature assessing the incidence of AKI in patients with cirrhosis, either with or without ascites, who have been submitted to surgical procedures.

The objective of this study was to analyze the renal function of patients with cirrhosis submitted to a correction of abdominal wall hernias. Furthermore, it aimed to compare patients presenting acute kidney injury with others, to determine risk factors for its occurrence.

\section{METHODS}

This study was approved by the Scientific Ethic Committee of the Department of Gastroenterology School of Medicine University of São Paulo, São Paulo, SP, Brazil) and is in agreement with all requirements of the Helsinki Declaration, 1975.

This is a retrospective cohort between 2001 and 2014, with analysis of medical records between 2001 and 2009 and analytical, longitudinal collection of prospective data from 2009 to 2014. Patients over the age of 16 with cirrhosis and abdominal hernias who underwent surgical correction of the hernias were included. These patients were monitored during hospitalization and in outpatient clinic during the postoperative phase.

The ones submitted to elective and emergency surgery were assessed and followed. The indications for emergency surgery were: hernial strangulation, painful irreducible hernia, skin perforation with extravasation of ascitic fluid or ischemic ulceration of the skin. These cases were submitted to emergency herniorrhaphy. The following demographic and clinical variables of the patients were assessed: gender, age, BMI (body mass index), etiology of cirrhosis, Child score, MELD score, patient's inclusion on the liver transplantation waiting list, ascites volume, diabetes, presence of TIPS(transjugular intrahepatic portosystemic shunt), types of hernia, and the presence of previous complications from hernias. The data were collected prior to surgery, in the pre-operative phase, or at hospitalization in emergency cases.

The laboratory tests were collected immediately before the surgery were: creatinine, INR (international normalized ratio), total bilirubin, sodium. Ten grams of human albumin were intravenously administered per liter of ascitic fluid removed during surgery. In cases of voluminous ascites in the postoperative phase, a relief parecentesis was carried out where there was tense ascites, and always with albumin expansion when the volume was over $5 \mathrm{I}$, in a dose of $10 \mathrm{~g}$ of albumin per liter removed ${ }^{10}$.

Patients were divided into two groups: patients with AKI and without $\mathrm{AKI}$ after surgery.

Laboratorial tests were collected in the immediate postoperative phase, on the $1^{\text {st }}, 3^{\text {rd }}$ and $5^{\text {th }}$ postoperative days: creatinine, INR, total bilirubin and sodium. The patients not displaying complications were discharged on the $5^{\text {th }}$ postoperative day. In cases where there were significant alterations in results, or a clinical complication, the exams were carried out daily. Diuretics were not introduced in the early post-operative phase for these patients. It was done only at hospital discharge, or after the $5^{\text {th }}$ day without AKI signs. The patients who developed AKI received treatment with albumin, with initial doses of $10 \mathrm{~g}$ administered three times per day ${ }^{10,18}$. Patients who showed no improvement of renal function after albumin treatment received terlipressin in initial doses of $0.5 \mathrm{mg}$, four times per day.

\section{Statistical analysis}

Quantitative variables are presented as mean, median, standard-deviation, range, interquartile range. The qualitative variables are presented as absolute frequency and percentage. To verify the behavior of the variables in each group across time, ANOVA was used for repeated, non-parametric measures. To verify the differences between groups of quantitative variables, the Kolmogorov-Smirnov was first used to assess normality. When the supposition of normality was not rejected, the Student's t-test was used, if it was, the Wilcoxon-Mann-Whitney was used. Fisher's exact test was used to assess the relation between qualitative variables. Kaplan-Meier estimates were used to create the survival curves for each group, and the log-rank test to assess whether the variables were different. Cox's model was used to verify which quantitative variables were associated with mortality. The level of significance adopted was $5 \%$.

\section{RESULTS}

Were included 174 patients who underwent procedures to correct hernias of the abdominal wall. The mean follow-up time was 2.58 years, with a median of 2.3 years (8-2241 days). The mean age was $53.71 \pm 11.66$ years (Table 1 ). In the population, 135 patients were male, corresponding to $77.6 \%$.

The majority of patients were Child B (53.4\%), followed by Child A (25.3\%) and C (19\%).

From the total of patients who underwent surgery $27.3 \%$ had light ascites; $22.4 \%$ moderate; $13.2 \%$ voluminous; and $17.8 \%$ did not have. Of the patients with ascites, $47.9 \%$ had previously undergone paracentesis.

With regards to hernia type, 126 patients had umbilical hernias (72.4\%). This was the most common hernia in the evaluated population, and 58 had inguinal hernias (33.3\%). Of these, 14 (8\%) were bilateral and 10 (6.0\%) had incisional hernias.

Among the entire group $(n=174), 88$ underwent elective and 83 (48.5\%) emergency surgery. In total, 78 (48.5\%) had surgical complications.

\section{Comparison between patients with and without postoperative AKI}

A total of 58 patients (34.9\%) had postoperative AKI. Table 2 shows the base creatinine and creatinine of each group in the immediate postoperative phase, and on the $1 \stackrel{\text { st }}{3^{\text {rd }} \text { and }}$ $5^{\text {th }}$ postoperative days. 
The interaction was statistically significant. Creatinine behaved differently over time, depending on the group. In the group that had postoperative AKI, there was an increase in creatinine over time, while in the group that did not have postoperative AKI there was a small increase, followed by a decrease (after $\mathrm{Cr} 3$, Figure 1).

\section{Comparison of groups (postoperative AKI)}

The variables were tested in relation to the presence of postoperative AKI. There was a significant difference between the groups in the following variables: initial MELD, base creatinine and immediate postoperative creatinine (Table 3 ). In all variables the postoperative AKI group had higher means than the group without postoperative AKI. There was no difference observed in age or BMI. AKI.

There was no relation between etiology and postoperative

In the AKI group, $37.9 \%$ had moderate ascites, while in the group without $A K I$, only $15.7 \%$ did $(p=0.0001)$, indicating an association between the degree of ascites and postoperative AKI.

In the AKI group, $69.1 \%$ had undergone paracentesis, while, in the group without AKI, only $38.1 \%$ had $(p=0.0002)$. Moreover, in the AKI group, a larger number of patients underwent emergency surgery (Table 4).

In patients with postoperative AKI, there was a larger proportion of individuals with postoperative complications (Table 4).

\section{Analysis of survival}

The variables were analyzed in relation to patient survival. The presence of ascites, surgery, surgical complications and postoperative AKI were significantly related to survival (Table 5).

Table 1 - Clinical and laboratory characteristics of the 174 patients operated for abdominal wall hernias

\begin{tabular}{lcc} 
Variable & Mean & $\mathbf{( 1 )}$ \\
\hline Age & 53.71 & 11.66 \\
\hline BMI & 25.78 & 4.31 \\
\hline Time & 1238.06 & 1104.06 \\
\hline MELD Initial & 13.00 & 6.00 \\
\hline Cr basal & 1.17 & 0.69 \\
\hline Cr POI & 1.27 & 1.84 \\
Cr1 & 1.44 & 1.01 \\
Cr3 & 1.52 & 1.30 \\
Cr5 & 1.40 & 1.13 \\
Cr10 & 1.44 & 1.01
\end{tabular}

$\mathrm{BMI}=$ body mass index; $\mathrm{MELD}=$ Model for End-Stage Liver Disease $\mathrm{Cr}=$ creatinine $\mathrm{PO}=$ postoperative day; $\mathrm{POI}=1^{\text {st }} \mathrm{PO} ; \mathrm{Cr} 1=$ creatinine on $1^{\text {st }} \mathrm{PO} ; \mathrm{Cr} 3$ creatinine on the $3^{\text {rd }} \mathrm{PO} ; \mathrm{Cr} 5=$ creatinine on the $5^{\text {th }} \mathrm{PO} ; \mathrm{Cr} 10=$ creatinine on the $10^{\text {th }} \mathrm{PO} .(1)$ internalization (standard-deviation)
The variables age, initial MELD, base creatinine and creatinine in the immediate postoperative phase were statistically significant, meaning that the risk ratio is different to 1 . For each year of age, the risk of mortality increases by 1.0328 (or increases by $3.28 \%$ ). In base creatinine, for each increase in unit, the risk of mortality increases by 1.514 (Table 6).

Three different models for multivariate analysis were carried out using Cox models. The variables in each model were: model 1: age, initial MELD and base creatinine; model 2: age, initial MELD and IPO creatinine; model 3: age, initial MELD and creatinine delta (difference between IPO creatinine and base creatinine).

In model 1, the variable base creatinine was not statistically significantly related. The other variables had a risk ratio greater than 1 , indicating that they were risk factors for mortality (Table 7). In model 2,immediate postoperative creatinine was not statistically significant. The other two factors again had a risk ratio greater than 1 , indicating that they are risk factors for mortality (Table 7). In model 3, delta creatinine was not statistically significant. The other two factors again had a risk ratio greater than 1 , indicating that they are risk factors for mortality (Table 7).

\section{DISCUSSION}

This study of 174 patients represents the largest renal function behavior analysis of patients with cirrhosis undergoing abdominal hernia correction operated on in the same service. This is the first study that assesses kidney function in the postoperative phase and risk factors for renal damage. The main prognostic factors related to survival were: the presence of ascites, umbilical hernia, inguinal hernia, type of surgery, postoperative complications and postoperative AKI.

There is a lack of perioperative studies that show the assessment and evolution of the results of surgery in patients with cirrhosis and complications(9), and this study aimed to identify risk factors for AKI in this population.

This surgery is carried out more frequently today than in the past, in part due to the increased long term survival of patients with cirrhosis. Recent studies have concentrated on estimating perioperative risk in patients with liver disease ${ }^{15}$. Hemodynamic instability in the perioperative period can worsen hepatic function in patients with cirrhosis ${ }^{8}$. The operative risk is correlated with the severity of liver disease and the type of surgical procedure. Detailed evaluation is necessary prior to elective surgery in these patients. The estimated perioperative mortality is unknown due to the retrospective nature and selection bias in published clinical studies. Child-Pugh classification, and particularly MELD score give reasonable estimates for

Table 2 - AKI PO and base creatinine, POI, $1^{\text {st }} 3^{\text {rd }}$ and $5^{\text {th }} \mathrm{PO}$

$\begin{array}{lcccccccc}\text { AKI PO } & \text { Creatinine } & \text { Mean } & \text { Median } & \text { Standard deviation } & \text { Min } & \text { Max } & \mathbf{1}^{\text {st Quartile }} & \mathbf{3}^{\text {rd }} \text { Quartile } \\ & \text { Cr base } & 1.019 & 0.920 & 0.579 & 0.510 & 6.080 & 0.770 & 1.100 \\ \text { No } & \text { Cr FPD } & 1.039 & 0.910 & 0.708 & 0.000 & 6.560 & 0.920 & 1.690 \\ & \text { Cr1 } & 1.170 & 1.070 & 0.916 & 0.000 & 7.710 & 0.815 & 1.100 \\ & \text { Cr3 } & 1.149 & 1.000 & 1.338 & 0.000 & 11.340 & 1.070 & 2.170 \\ & \text { Cr5 } & 0.841 & 0.820 & 0.726 & 0.000 & 2.460 & 0.800 & 1.400 \\ & \text { Cr base } & 1.456 & 1.240 & 0.804 & 0.560 & 4.620 & 1.205 & 2.400 \\ & \text { Cr FPD } & 1.692 & 1.350 & 0.928 & 0.580 & 4.720 & 0.690 & 1.410 \\ \text { Yes } & \text { Cr1 } & 1.984 & 1.960 & 0.960 & 0.000 & 5.110 & 1.445 & 2.555 \\ & \text { Cr3 } & 2.198 & 2.100 & 0.918 & 0.560 & 4.400 & 0.000 & 1.320 \\ & \text { Cr5 } & 2.229 & 2.105 & 1.122 & 0.000 & 5.400 & 1.330 & 2.910\end{array}$

$\mathrm{AKI}=$ acute kidney injury; $\mathrm{PO}=$ postoperative day; $\mathrm{Cr}=\mathrm{creatinine} ; \mathrm{FPD}=1^{\text {stPO}} \mathrm{Cr} 1=$ creatinine in $1^{\text {st }} \mathrm{PO} ; \mathrm{Cr} 3=\mathrm{creatinine}$ in $3^{\text {rd }} \mathrm{PO} ; \mathrm{Cr} 5=\mathrm{creatinine}$ in $5^{\text {th }} \mathrm{PO} ; \mathrm{Cr} 10=\mathrm{creatinine}$ in $10^{\text {th }} \mathrm{PO} ; \mathrm{POI}=$ immediate postoperative 


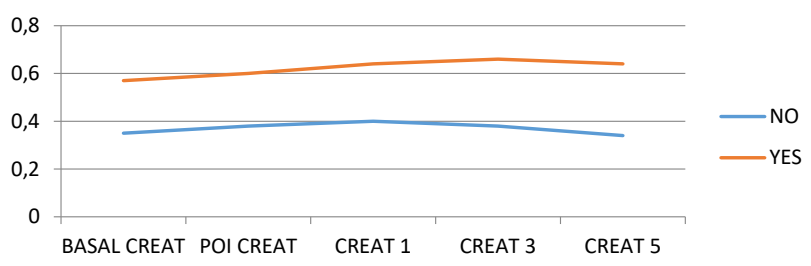

$\mathrm{CREAT}=$ creatinine; $\mathrm{POI}=$ immediate postoperative; Anova for non-parametric repeated measures; red line patients with AKl; black line without AKI.

Figure 1 - Postoperative creatinine in cirrhotic patients who underwent herniorraphies: $A$ ) red line with $\mathrm{AKI} ; \mathrm{B}$ ) blue line without AKI

Table 3 - Variables for the AKI group

\begin{tabular}{lcccc} 
Variable & AKI PO & Mean & $\begin{array}{c}\text { Standard } \\
\text { deviation }\end{array}$ & $\mathbf{p ~ ( 1 )}$ \\
\hline \multirow{2}{*}{ Age } & No & 53.86 & 11.54 & 0.7720 \\
& Yes & 52.79 & 11.87 & \\
\multirow{2}{*}{ BMI } & No & 25.83 & 3.99 & 0.5999 \\
& Yes & 25.47 & 4.69 & \\
Initial MELD & No & 12.00 & 4.00 & 0.0001 \\
& Yes & 14.00 & 4.00 & \\
Cr base & No & 1.02 & 0.58 & $<0.0001$ \\
& Yes & 1.46 & 0.80 & \\
Cr POI & No & 1.04 & 0.71 & $<0.0001$ \\
& Yes & 1.69 & 0.93 &
\end{tabular}

$\mathrm{BMI}=$ body mass index; MELD=Model For End-Stage Liver Disease; $\mathrm{Cr}=$ creatinine; $\mathrm{POI}=$ immediate postoperative. (1) Wilcoxon-Mann-Whitney test.

Table 4 - Postoperative AKI, elective surgery compared with emergency surgery and complications for patients with cirrhosis submitted to hernial correction

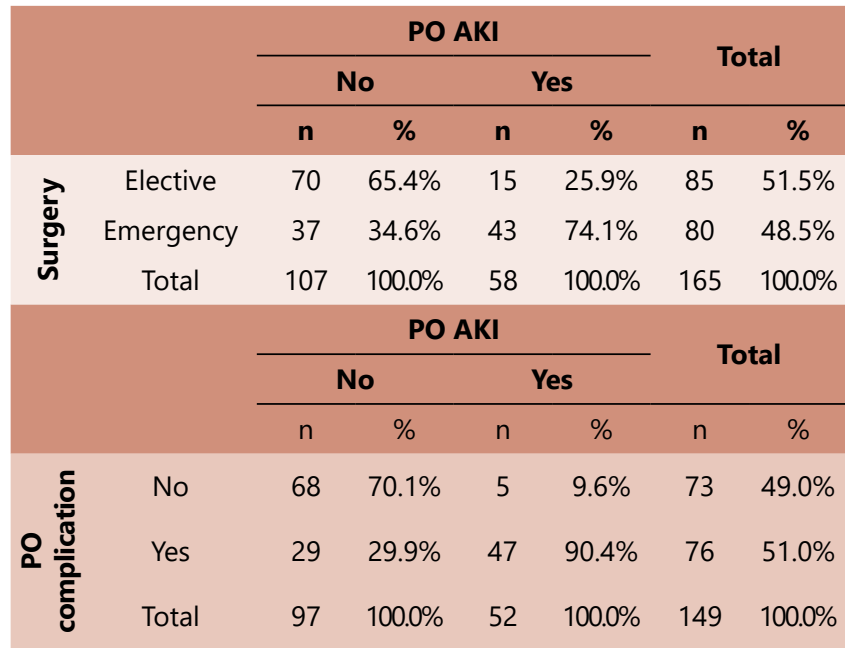

$\mathrm{p}<0.0001 ; \mathrm{AKI}=$ acute kidney injury; $\mathrm{PO}=$ postoperative

Table 5 - Analysis of factors related to patient survival of patients with cirrhosis submitted to hernial correction - qualitative variables

\begin{tabular}{lc} 
Variable & p (1) \\
Ascites & 0.0018 \\
\hline Surgery & $<0.0001$ \\
\hline Surgical complications & 0.0025 \\
PO AKI & 0.0001
\end{tabular}

$\mathrm{AKI}=$ acute kidney injury; $\mathrm{PO}=$ postoperative. (1) Log-rank test to determine whether or not the survival curves are different by Kaplan-Meier estimates.
Table 6 - Analysis of factors related to patient survival of patients with cirrhosis submitted to hernial correction - quantitative variables

\begin{tabular}{lcccc} 
Variable & Risk ratio & \multicolumn{2}{c}{$\mathbf{C l}(\mathbf{9 5}, \mathbf{0} \%)$ of RR } & P (1) \\
\cline { 3 - 4 } & & Minlim & Max lim & \\
Age & 1.0328 & 1.0079 & 1.0583 & 0.0096 \\
BMI & 0.9652 & 0.9006 & 1.0345 & 0.3167 \\
Initial MELD & 1.0942 & 1.0391 & 1.1522 & 0.0006 \\
\hline Base Cr & 1.5140 & 1.2372 & 1.8529 & 0.0001 \\
Cr POI & 1.3795 & 1.1402 & 1.6691 & 0.0009
\end{tabular}

$\mathrm{BMI}=$ body mass index; MELD=Model for End-Stage Liver Disease; $\mathrm{Cr}=$ creatinine; $\mathrm{POI}=$ immediate postoperative. (1) Univariate analysis of risk ratio (RR).

Table 7 - Multivariate analysis of factors related to survival of patients with cirrhosis who underwent hernial correction - Model 1, Model 2 and Model 3

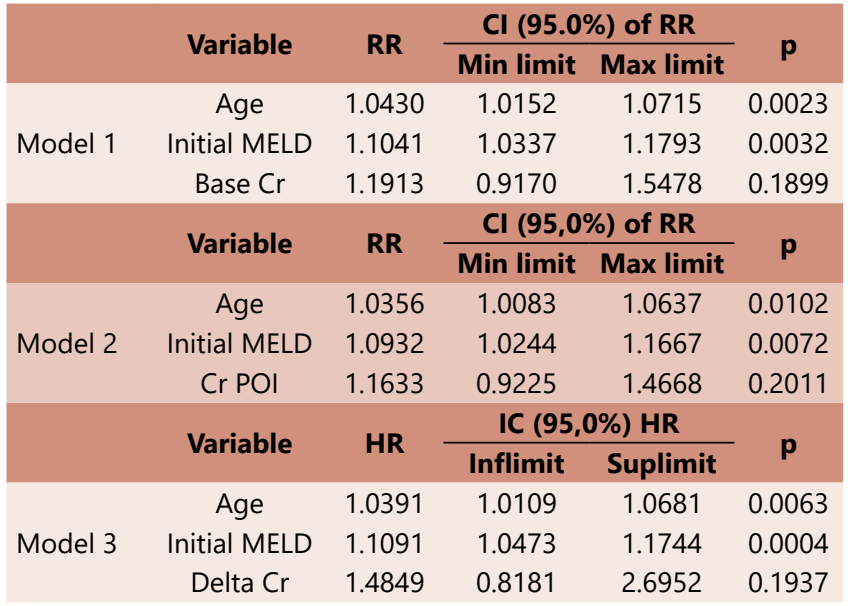

MELD=Model for End-Stage Liver Disease; $\mathrm{Cr}=$ creatinine; $\mathrm{POI}=$ immediate postoperative

perioperative mortality risk, but do not supplant the need for careful preoperative preparation and postoperative follow up, such as early detection of complications, which is essential to improve outcomes ${ }^{2}$.

The incidence of complications in this study was $44.8 \%$, with ascites leakage through the operative wound, hematoma of the operative wound and skin dehiscence as the most common. This reflects the high rate of complications in this group of patients, as shown in the literature ${ }^{2}$.

The majority of hernias operated in this study were umbilical, representing $72.4 \%$ of procedures. This prevalence in patients with cirrhosis is also reflected in the literature ${ }^{1}$.

Patients with cirrhosis have a high incidence of abdominal wall hernias, and following surgical correction, have a higher morbimortality. The ideal surgical strategy, as well as time to correct abdominal wall hernias is controversial ${ }^{14,16}$. The advantage of having this knowledge would be to predict which patients are at elevated risk of developing postoperative AKI. This would allow a choice wherever possible, of better preparation before the operation, or attempting a prior intervention or treatment to prevent hernia's appearance.

A cohort study by Andraus et al. ${ }^{1}$ evaluated 67 patients with cirrhosis submitted to hernial correction. The median MELD score was 14 (6-24). Emergency surgery was carried out in 34 patients due to hernial rupture $(n=13)$, incarceration $(n=10)$, strangulation $(n=4)$ and skin necrosis or ulceration $(n=7)$. Elective surgery was carried out in 27 cases. After a multivariate analysis, emergency surgery (OR 7.31; $p=0.017)$ and Child Pugh $C(O R 4.54 ; p=0.037)$ were risk factors for serious complications. 
Furthermore, emergency surgery was an independent risk factor for 30 days mortality (OR 10.83; $p=0.028)$. The risk of morbidity and mortality is associated with emergency surgery in patients with advanced cirrhosis.

As mentioned, majority of patients in this study was Child B (53.4\%), followed by Child A (25.3\%) and C (19\%) and the MELD score varied between 6 and 24 .

Kidney dysfunction in cirrhosis is mainly related to the development of $\mathrm{AKI}$, caused by acute hemodynamic alterations. It's incidence increases according to the presence of other associated risk factors that can cause alteration to kidney function, such as diabetes, viral hepatitis, among others. AKI is defined as an increase in serum creatinine of $0.3 \mathrm{mg} / \mathrm{dl}$ in $<48 \mathrm{~h}$ or of $50 \%$ of base creatinine over the past three months, without defining a threshold of final serum creatinine. Stages 1 , 2 and 3 of AKI are defined as 150\%, 200\% and 300\% of base serum creatinine, respectively, which allows assessment of the progression of $\mathrm{AKI}^{20}$.

Among the sample $(n=174) 58$ patients $(34.9 \%)$ had postoperative AKI, while 108 (65.1\%) did not. The factors related with $\mathrm{AKI}$ are initial MELD, base $\mathrm{Cr}$, immediate postoperative $\mathrm{Cr}$.

The main limitation of this study is being retrospective, meaning that it was not possible to verify results by comparing intervention with no intervention.

Abdominal wall hernia is a common complication for patients with cirrhosis. Herniorrhaphy presents a higher morbimortality when compared with patients without cirrhosis. The presence of $A K I$ in the postoperative is a frequent event and should be prevented when possible and treated adequately, in order to reduce mortality in this population.

Preoperative preparation with adequate volume expansion to replace ascites evacuation, careful hydration, an elective surgical approach, rigorous controls of hydration balance in the intra and postoperative phases are useful and effective measures to prevent AKI in patients with cirrhosis. As a consequence, a lower rate of morbimortality can be reached in this population when submitted to hernial correction surgery ${ }^{4}$

\section{CONCLUSION}

Patients with cirrhosis submitted to abdominal wall hernia surgical correction have a high incidence of worsening their kidney function, with development of AKI in the first postoperative days. The patients who develop AKI in the postoperative phase have a higher rate of complications and higher mortality. Alongside worsening liver function, the risk factors for developing AKI in the postoperative phase are the presence of ascites, elevated baseline creatinine and the need for emergency surgery.

\section{REFERENCES}

1. Andraus W, Pinheiro RS, Lai Q, Haddad LBP, Nacif LS, D'Albuquerque LAC, LerutJ. Abdominal wall hernia in cirrhotic patients: emergency surgery results in higher morbidity and mortality. BMC Surg 2015;15:65. doi: 10.1186/s12893-015-0052-y.2.

2. Befeler AS, Palmer DE, Hoffman M, Longo W, Solomon $\mathrm{H}$, Di Bisceglie AM. The safety of intra-abdominal surgery in patients with cirrhosis: model for end-stage liver disease score is superior to Child-Turcotte-Pugh classification in predicting outcome. Arch Surg. 2005;140(7):650-4. doi: 10.1001/archsurg.140.7.650.

3. Belcher JM, Garcia-Tsao G, Sanyal AJ, Bhogal H, Lim JK, Ansari N, Coca SG, Parikh CR; TRIBE-AKI Consortium. Association of AKI with mortality and complications in hospitalized patients with cirrhosis. Hepatology.2013;57(2):753-62. doi: 10.1002/hep.25735.

4. Bhangui $P$, Laurent A, Amathieu R, Azoulay D. Assessment of risk for non-hepatic surgery in cirrhotic patients. J Hepatol. 2012;57(4):874-84. doi: 10.1016/j.jhep.2012.03.037.

5. Bıyık M, Ataseven H, Bıyık Z, Asil M, Çifçi S, Sayın S, Tonbul HZ, Demir A. KDIGO (Kidney Disease: Improving Global Outcomes) criteria as a predictor of hospital mortality in cirrhotic patients. Turk J Gastroenterol. 2016;27(2):173-9. doi: 10.5152/tjg.2016.15467.

6. Freire EG, Albuquerque JCS, Leal IP, Sousa NA, Graça JRVD. Effect of chronic renal dysfunction on the permeability of the colon to water and electrolytes: experimental study in rats. Arq Bras Cir Dig. 2019;32(4):e1472. doi: 10.1590/0102-672020190001e1472.

7. Freitas ACT, Coelho JCU, Watanabe MR, Lima RLDC. Relationship between donor quality and recipient gravity in liver transplant. Arq BrasCirDig.2020;33(1):e1499.doi:10.1590/0102-672020190001e1499

8. Friedman LS. Surgery in the patient with liver disease. Trans Am Clin Climatol Assoc. 2010;121:192-204; discussion 205. PMID: 20697561

9. Furtado M, Claus CMP, Cavazzola LT, Malcher F, Bakonyi-Neto A, Saad-Hossne R. Systemization of laparoscopic inguinal hernia repair (TAPP) based on a new anatomical concept: inverted y and five triangles. Arq Bras Cir Dig. 2019;32(1):e1426. doi: 10.1590/0102$672020180001 \mathrm{e} 1426$

10. Gerbes AL. The patient with refractory ascites. Best Pract Res Clin Gastroenterol.2007;21(3):551-560. doi: 10.1016/j.bpg.2006.12.001

11. Gerbes AL. Liver Cirrhosis and Kidney. Dig Dis. 2016;34(4):387-390. doi: 10.1159/000444553

12. Ginès $P$, Solà $E$, Angeli $P$, Wong $F$, Nadim MK, Kamath PS. Hepatorenal syndrome. Nat Rev Dis Primers. 2018;4(1):23. doi: 10.1038/s41572018-0022-7. Erratum in: Nat Rev Dis Primers. 2018;4(1):33. PMID: 30213943.

13. Lei L, Li L, Zhang H. Advances in the Diagnosis and Treatment of Acute Kidney Injury in Cirrhosis Patients. Biomed Res Int. 2017;2017:8523649. doi: 10.1155/2017/8523649.

14. Licari L, Salamone G, Ciolino G, Campanella S, Parinisi Z, Sabatino C, Carfi F, Bonventre S, Gulotta G. The abdominal wall incisional hernia repair in cirrhotic patients. G Chir. 2018;39(1):20-23. doi: 10.11138/gchir/2018.39.1.020.

15. Lopez-Delgado JC, Ballus J, Esteve F, Betancur-Zambrano NL, Corral-Velez V, Mañez R, Betbese AJ, Roncal JA, Javierre C. Outcomes of abdominal surgery in patients with liver cirrhosis. World J Gastroenterol. 2016;22(9):2657-67. doi: 10.3748/wjg.v22. i9.2657.

16. Myers SP, Kulkarni SS, Malik SM, Tevar AD, Neal MD. Hernia Management in Cirrhosis: Risk Assessment, Operative Approach, and Perioperative Care. J Surg Res. 2019;235:1-7. doi: 10.1016/j. jss.2018.09.052

17. Rahimi RS, Rockey DC. Complications of cirrhosis. Curr Opin Gastroenterol.2012;28(3):223-9.doi:10.1097/MOG.0b013e328351d003.

18. Regner KR, Singbartl K. Kidney Injury in Liver Disease. Crit Care Clin. 2016;32(3):343-55. doi: 10.1016/j.ccc.2016.03.005.

19. Velez JCQ, Therapondos G, Juncos LA. Reappraising the spectrum of AKI and hepatorenal syndrome in patients with cirrhosis. Nat Rev Nephrol.2020;16(3):137-155. doi:10.1038/s41581-019-02184. Epub 2019 Nov 13. Erratum in: Nat Rev Nephrol. 2020 Jan 27; PMID: 31723234.

20. Wong F. Diagnosing and treating renal disease in cirrhotic patients. Minerva Gastroenterol Dietol. 2016;62(3):253-66. 